\title{
Control and Management of Thickened Tailings Beach — A Simplified Approach
}

\author{
D. Luppnow SRK Consulting, Australasia \\ J. Moreno SRK Consulting, Australasia \\ M. Palape SRK Consulting, South Africa
}

\begin{abstract}
Prediction of the beach slope profile in thickened tailings disposal is currently being approached by methods based on empirical expressions or by undertaking pilot plant trials. In order to estimate the beach slope using empirical methods, it is generally necessary to know the flow rate of the slurry, its density, its solids content and the rheology of the slurry

The rheology of the slurry is usually described using the Herschel-Bulkley model or Bingham plastic model. These models require a laboratory test programme to estimate the yield stress, viscosity and the HerschelBulkley indices. This process can be time consuming and expensive for high level engineering design, and for ongoing control and management of tailings beach.

The Esperanza thickened tailings project included a pilot plant where several laboratory tests were developed for various solids content. The resulting data was used as an input for the beach slope estimation method based on non-Newtonian open channel flows.

The results of the prediction indicated that there is a strong correlation between the yield stress and the beach slope.

Considering the yield stress as an indicator of the beach slope, a method for control and management of beach slope is suggested.

Prediction of the tailings beach has been significantly researched during the last years and there are few methods currently available from the literature. SRK has used a simplified method to predict and control tailings beach. Experiences with conventional operations in South Africa (platinum tailings spigotting) and TTD systems in Australia were combined and applied for the Esperanza tailings system design where disposal strategy consists in using multiple spigots to actively manage the beach to achieve the required slope.
\end{abstract}

\section{$1 \quad$ Introduction}

SRK undertook the design of the thickened tailings facility for the Esperanza project. The Esperanza tailings facility will be one of the largest thickened tailings facilities in the world and has been designed to achieve a $4 \%$ beach slope. In general, for the design of thickened tailings deposits, a good estimation of the beach slope is one the most important factors when calculating the total capacity of a given basin.

It is known that the beach slope can be affected by several factors such as: solids content, viscosity, flocculants, size particle distribution, flow rate, among others. In addition, many of these factors also depend on the material extracted from the mine which, by definition, is variable and heterogeneous.

Considering the importance of the beach slope, two prediction methods were used to estimate the beach slope. These methods are based on rheological and geotechnical properties of the material and the energy of deposition. This energy can be expressed in terms of speed, flow rate or differential head, depending on the method being used.

The various test results were analysed and used as input for the methods of prediction and a bandwidth with the probable beach slopes varying disposal conditions was obtained. 
This paper took into account the variable nature of the slurry and presents a control procedure to manage the beach slope using only the slurry yield stress.

\section{Esperanza project}

The nominal tailings production from Minera Esperanza will be 95,000 dry $\mathrm{t}$ per day and the deposit is currently designed to accommodate $500 \mathrm{Mt}$.

The storage capacity of the basin was optimised to contain all of the tailings production considering a deposition beach slope of $4 \%$ and an average dry density of deposition of $1.6 \mathrm{t} / \mathrm{m}^{3}$.

The implementation of a suitable distribution system and control of tailings disposal to achieve the designed beach slope and density is thus extremely important.

The deposition beach slope of the thickened tailings for Esperanza was estimated from laboratory testing, two pilot plants campaigns and previous experience in projects that had similar conditions. Two models were produced using results of rheological tests conducted by CETTEM at the University of Concepcion, and a later batch tested by Rheological Laboratory of PSI Brazil in Belo Horizonte, Brazil.

\section{Pilot plant estimation beach slope}

Two bench scale tailings disposal campaigns were conducted using tailings from a pilot plant. Four single cone riser deposition tests and three channel tests were carried out in the facilities of CIMM (Santiago, Chile); and one single cone riser deposition test was carried out at the project site (northern Chilean desert). The test onsite was undertaken to evaluate the effect of the desert weather conditions at the proposed disposal site.

The single cone riser deposition tests carried out at the CIMM facilities achieved a range of solid contents between 60 and $72 \%$ and resulted in deposited beach slopes of between 4 and $12 \%$.

The channel tests carried out at the facilities of CIMM with similar range of solids content (between 64 and $66 \%$ ), resulted in beach slopes of between 3 and $6 \%$.

The single cone riser deposition test carried out at the project site achieved a range of solids content of between 57 and $70 \%$ (average of 66\%), and resulted in deposited beach slopes of between 9 and 12\%.

The high values of beach slope observed in the cone riser deposition tests can be explained by the scale factor and because they were developed under laminar flow conditions. It is known that the experimental beach slopes are generally steeper than beach slopes seen in the full-scale tailings deposition (Simms, 2007).

The beach slope observed in the various tests confirmed the possibility of having beaches with slopes of around $4 \%$, provided that the flow rate and solids content are managed properly.

\section{$4 \quad$ Estimation of the deposition beach slope based on empirical methods}

The empirical prediction of the beach slope used for the Esperanza project was based on the critical velocity concept. This velocity determines the change of the flow regime from laminar to turbulent.

The analysis considers an open channel self-formed by the fresh slurry running over the deposit. The objective is to determine the 'slope of equilibrium' of this channel, which will ultimately be the overall beach slope of the deposit (Pirouz et al., 2005; 2007).

The 'slope of equilibrium' is the slope necessary for the slurry to flow with critical velocity, which is capable of holding all the particles in motion without sedimentation or erosion occurring at the bottom of the channel.

The channels, formed naturally in the tailings surface, have an irregular cross section similar to a parabola (Pirouz et al., 2007). However, from the study conducted by Fitton et al. (2007) it was concluded that the shape of the cross section used to determine the 'slope of equilibrium' does not have much influence in the results. Therefore the beach estimation analyses were conducted considering a rectangular cross section with a 4:1 relationship between the base and the height, as recommended by Fitton et al. (2007). 
Considering that most of the mineral slurries follow a yield pseudoplastic behaviour (Paterson and Cooke, 2007), the critical velocity was estimated expressing the shear stress in terms of Bingham plastic model instead of the usual Herschel-Bulkley parameters.

Figure 1 presents the yield stress test results for selected solids content. The yield stress was determined using both slump tests and vane tests.

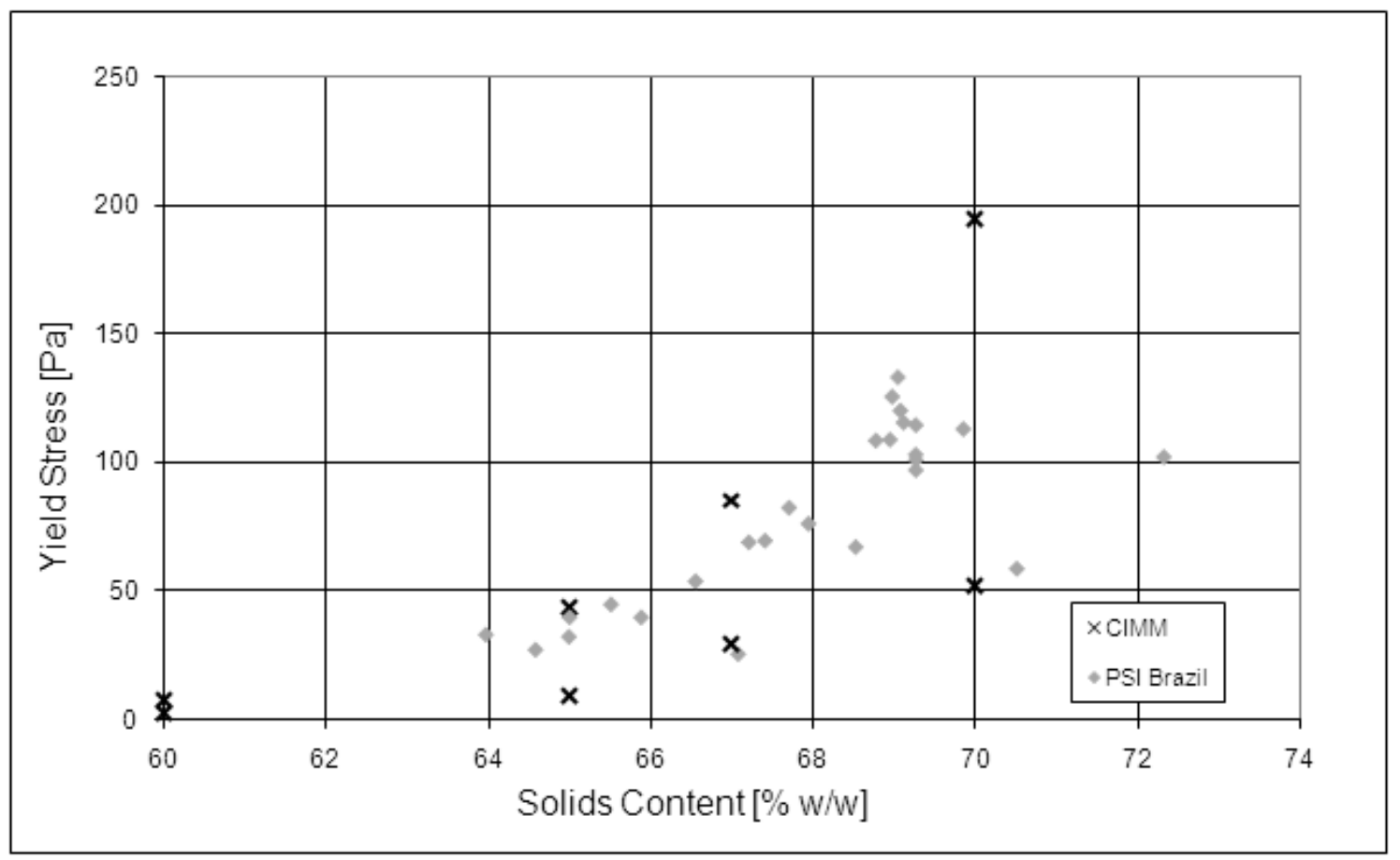

\section{Figure 1 Results of yield stress versus solids content}

The beach slope model was developed considering that the tailings flow will be distributed through spigots, given that the flow rate for the Esperanza project is high, around $1 \mathrm{~m}^{3} / \mathrm{s}$. The latter was introduced in order to determine the relationship between solids content, flow rate and beach slope.

\section{$5 \quad$ Results of simulations}

The distribution of the tailings into 20,10 and 2 spigots was analysed using the model and beach slopes were computed for each case. Figures 2, 3 and 4 show the variation of the beach slope with solids content for the various scenarios studied.

It can be observed that the beach slope ranges from 3.5 to $5 \%$ for the 20 spigot discharge, while for the 10 spigot discharge varies from 3 to $4 \%$, and the 2 spigot configuration from 2 to $3 \%$.

The computed beach slopes were plotted against the corresponding yield stress and the results are shown in Figure 5. It can be observed that there is a linear relationship between the beach slope and the yield stress.

This correlation may be useful for controlling the beach slopes during operation, as yield stress measurements of the slurry can be easily implemented as a routine test. 


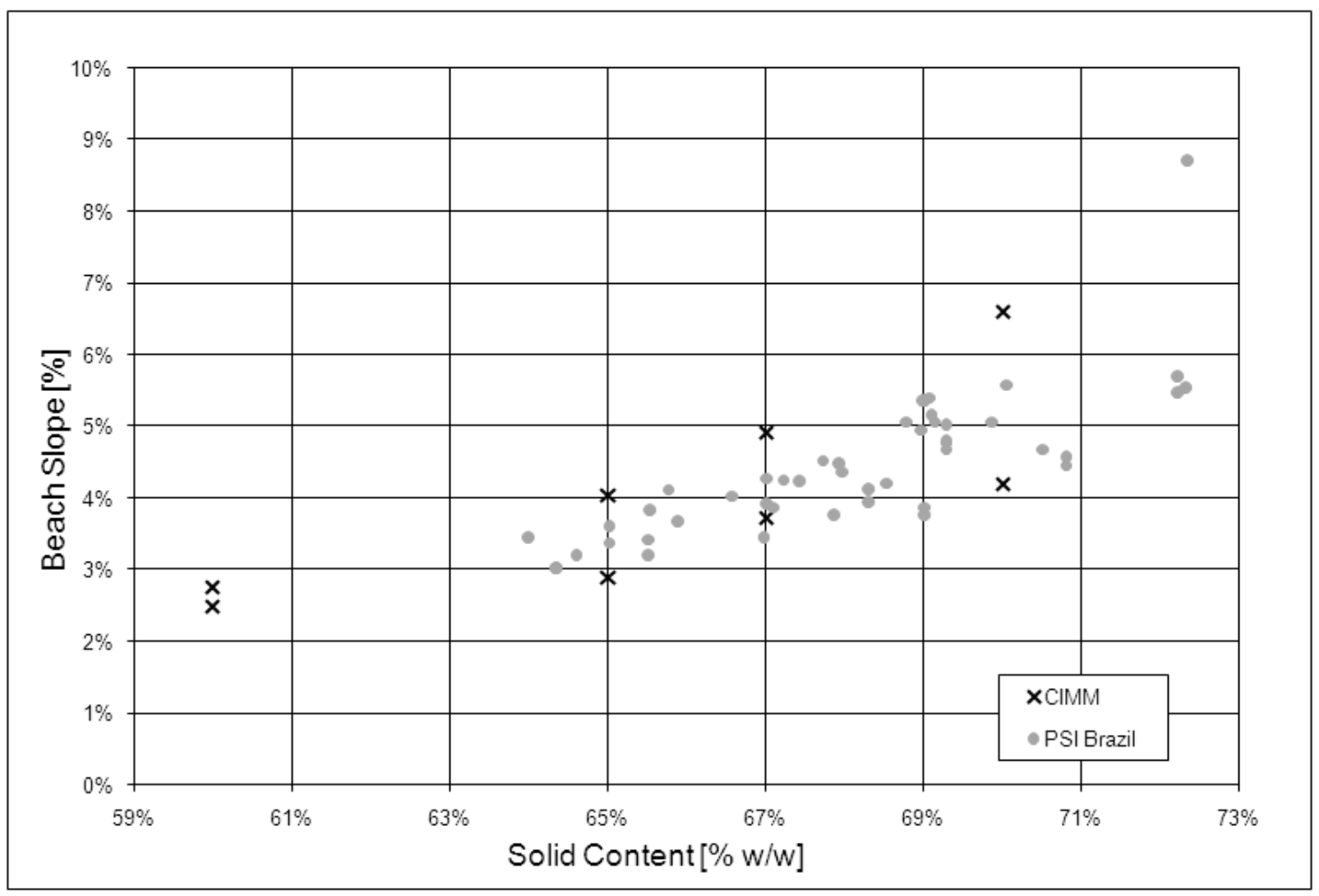

Figure 2 Variation of predicted beach slope with solids content considering 20 channels

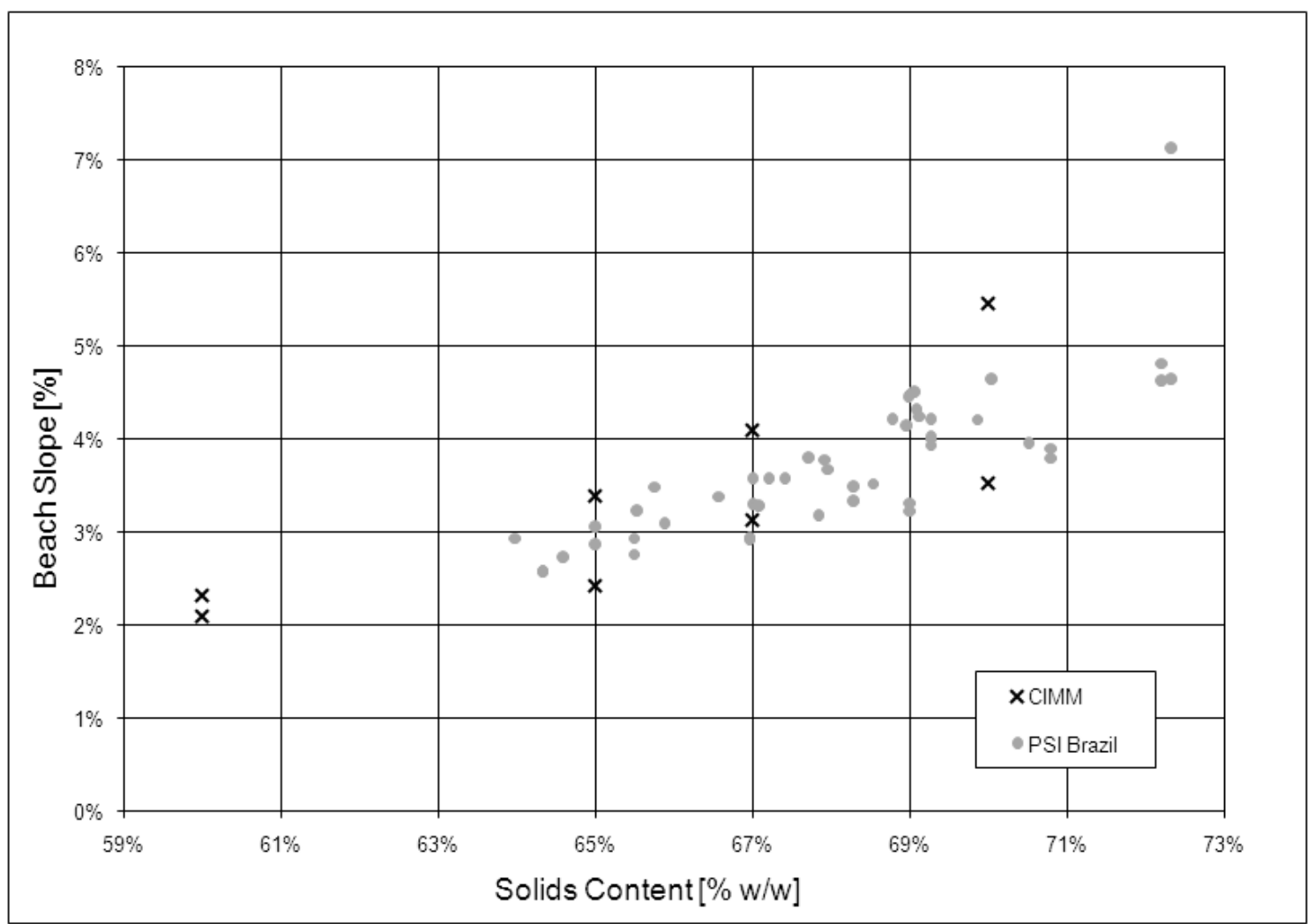

Figure 3 Variation of predicted beach slope with solids content considering 10 channels 


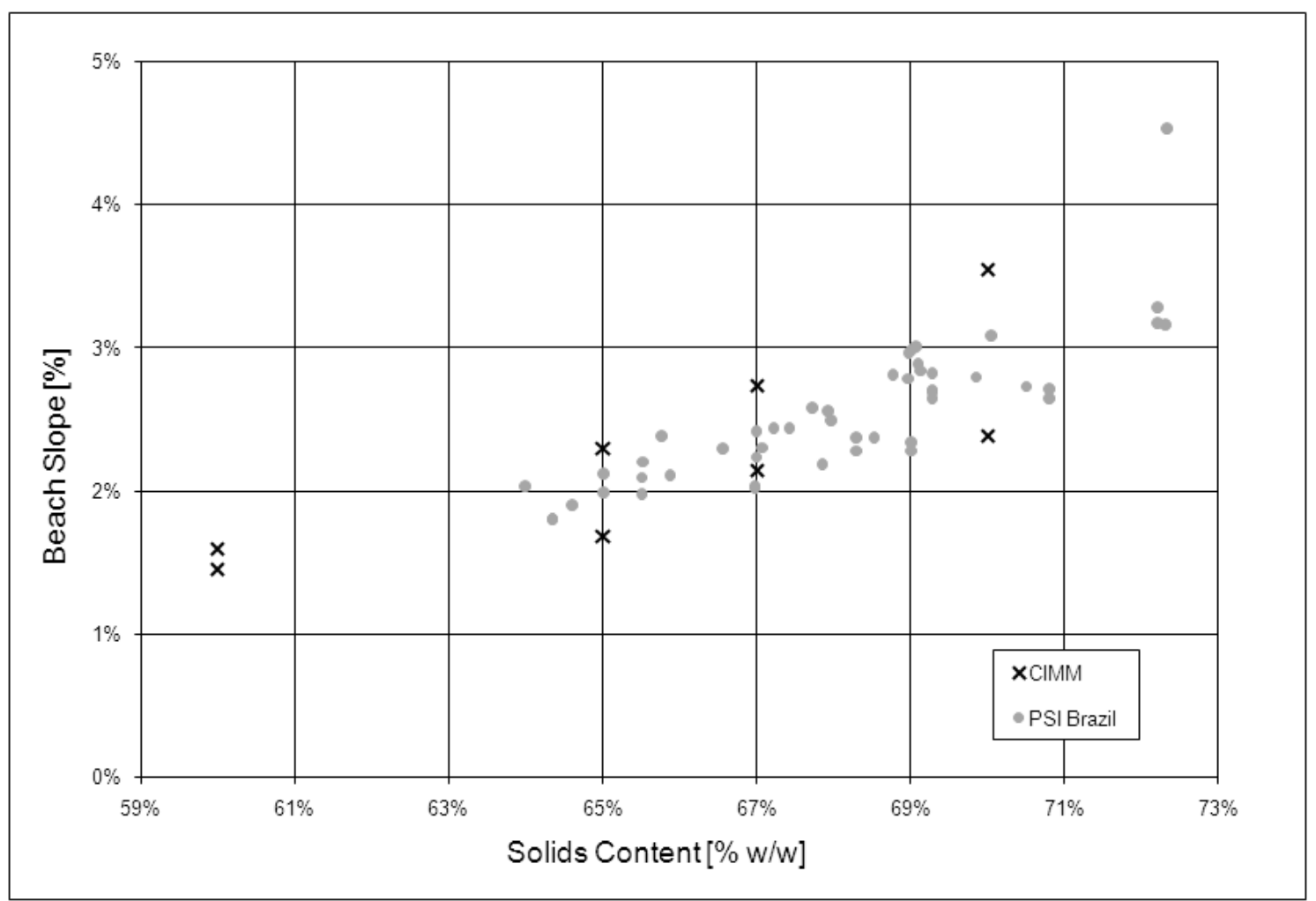

Figure 4 Variation of predicted beach slope with solids content considering 2 channels

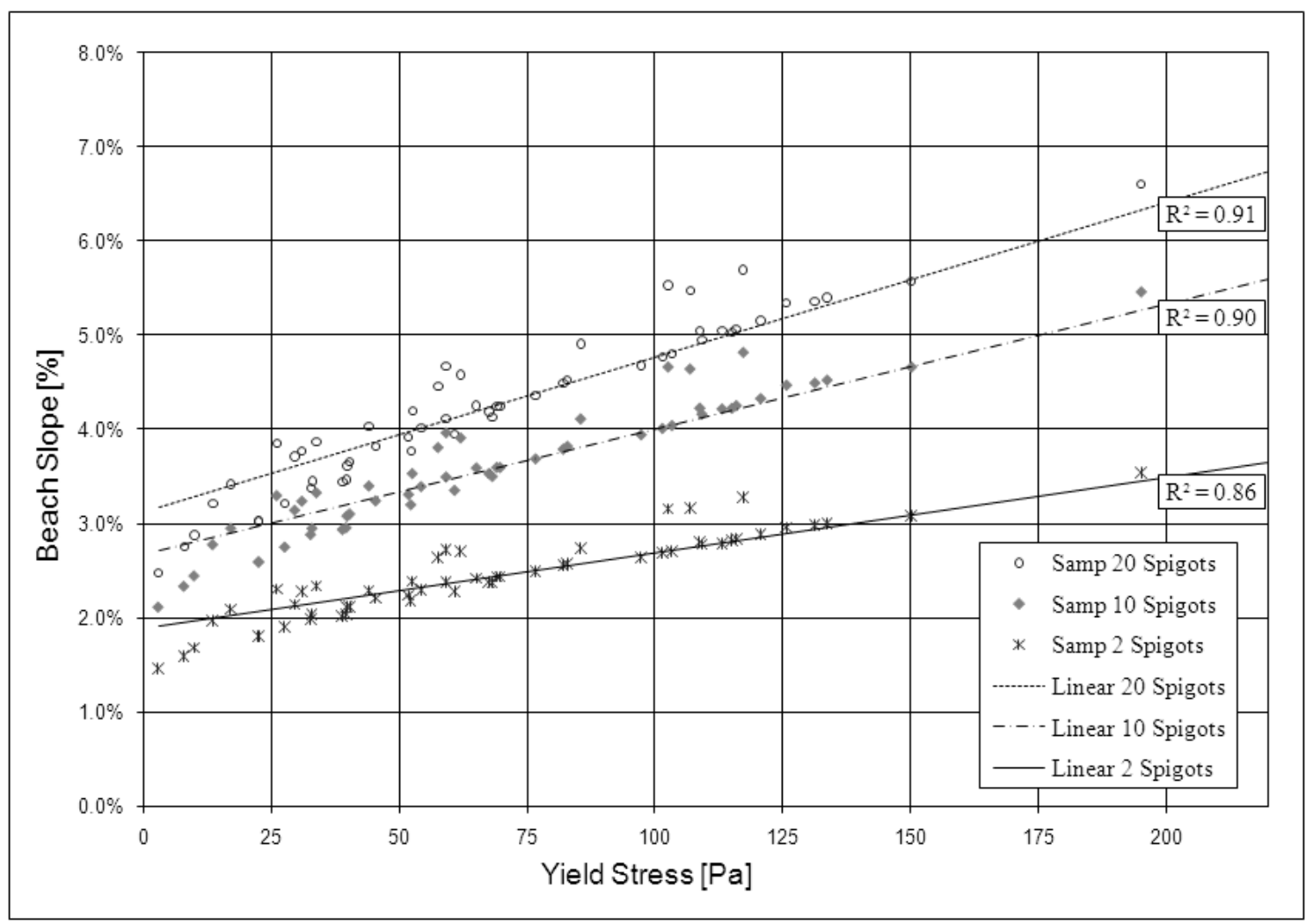

Figure 5 Variation of predicted beach slope with yield stress 


\section{Proposed beach slope management}

Having the flow rate distributed into 20 spigots could be conservative because it is highly probable that the beach slopes would reach an average of $4 \%$, however it is energy consuming. It could be convenient, at least during early operation of the facility, to use fewer spigots even when it would yield flatter beach slopes. It should be noted that flat beach slopes may be best suited to covering the alluvium basin with tailings faster.

Once most of the basin is covered with tailings, then deposition could be managed to steepen up the beach slope, as required. This could be attained by controlling the number of spigots in agreement of a desired beach slope based on yield stress measurements of the slurry stream. The variation in the number of spigots used is already used at a number of operational thickened tailings facilities to control beach slope. The results presented in this paper are specific for the Esperanza project, but have been developed empirically and for fixed tailings underflow solids content.

All the beach slopes estimated in this paper are based on semi-empirical expressions and testing observation for the various bench scale tailings disposal campaigns. Because they are estimated beach slopes, the observed real beach slope may vary from the design. The proposed beach slope management is based on learning the behaviour of the slurry, and using the yield stress parameter as an indicator to predict operational beach slopes.

As part of the operational manual for the Esperanza project it has been proposed that the relationship between the yield stress and beach slope be evaluated during commissioning and operation of the facility. This would be undertaken by performing regular series of slump tests or vane tests, measure solids content of the tailings delivered from the thickener and measuring the beach slopes attained per number of spigots opened. The objective is to develop an operational base knowledge that would allow the tailings manager to estimate the optimum number of spigots that may be opened to achieve a desired beach slope.

\section{Conclusions}

The rheology of slurry varies constantly having several factors influencing the interaction between the solid particles at any given time. However, the investigation conducted for the Esperanza project shows that there could be a good correlation between deposited beach slopes and the number of spigots used for specific tailings solids content. On the other hand, the ore from the mine normally would produce heterogeneous slurry mixtures. Therefore, it is not feasible to achieve a fixed tailings rheology. However, it has been proved that the deposited beach slopes can be managed by manipulating the number of operating spigots.

This investigation suggests that given that the yield stress correlates well with beach slopes, the measurement of the yield stress of the tailings prior to dispose should be implemented on a regular basis. This could be valuable as a decision-making tool for the tailings operators to manage their tailings beach slopes according to the project needs at any given time.

\section{References}

Fitton, T.G., Williams, M.P.A., Seddon, K.D., Bhattacharya, S.N. and Chryss, A.G. (2007) Simulation of thickened tailings stacks, Proceedings of the Tenth International Seminar on Paste and Thickening Tailings, A.B. Fourie and R.J. Jewell (eds), Australian Centre for Geomechanics, Perth, Australia, pp. 305-313.

Paterson, A. and Cooke, R. (2007) Thickened and paste tailings transportation course. November 2007. Santiago, Chile.

Pirouz, B. and Williams, M.P.A. (2007) Prediction of non-segregating thickened tailings beach slope - a new method, Proceedings of the Tenth International Seminar on Paste and Thickening Tailings, A.B. Fourie and R.J. Jewell (eds), Australian Centre for Geomechanics, Perth, Australia, pp. 315-327.

Pirouz, B., Kavianpour, M.B. and Williams, P. (2005) Thickened tailings beach deposition. Field observation and fullscale flume testing, Proceedings of the Eighth International Seminar on Paste and Thickening Tailings, R.J. Jewell and S. Barrera (eds), Australian Centre for Geomechanics, Perth, Australia, pp. 53-72.

Simms, P. (2007) On the relation between laboratory flume tests and depositions angles of high density tailings, Proceedings of the Tenth International Seminar on Paste and Thickening Tailings, A.B. Fourie and R.J. Jewell (eds), Australian Centre for Geomechanics, Perth, Australia, pp. 329-335. 